\title{
SIMULATION STUDY ON THE ARTIFICIAL ECOSYSTEM OF MARINE RANCHING AT DALIAN ZHANGZI ISLAND
}

\author{
WANG, G. ${ }^{12^{*}}-$ GUAN, X. X. ${ }^{1}-$ SHI, Y. H. ${ }^{1}$ \\ ${ }^{1}$ School of Geography, Liaoning Normal University, Dalian 116029, China \\ ${ }^{2}$ Southern Marine Science and Engineering Guangdong Laboratory (Guangzhou), Guangzhou \\ 511458, China \\ ${ }^{*}$ Corresponding author \\ e-mail: wanggeng@lnnu.edu.cn \\ (Received 26 ${ }^{\text {th }}$ Aug 2020; accepted $30^{\text {th }}$ Nov 2020)
}

\begin{abstract}
This study is based on the Vensim model with the Yesso scallop food chain as the core, combined with the multiple feedback effects of functional groups and environmental changes, to build an ecologicalenvironment-economy system dynamics simulation model of marine ranching, which is both human and natural Multi-factor feedback scenarios are simulated and predicted. The research results show that under natural conditions, the yield of Yesso scallop is mainly affected by natural disasters, with a stable period of about 10 billion grains, and the output value fluctuates around 10,236,922 EUR. The four controllable variables, fishing policy, development environment of Yesso scallop, sudden major natural disaster coefficient, and long-thorn starfish outbreak coefficient, have the most significant impact on Yesso scallop production. The large-scale outbreak and sudden large-scale outbreak of the long thorn starfish natural disasters can cause destructive production reductions in the Yesso scallop, but the local economic losses can be minimized through human control. The simulation model provides a scientific and feasible method for exploring the ecological elasticity of marine ranches and the maximum output of economic species.
\end{abstract}

Keywords: ecosystem, system dynamics, ecological restoration, multi-scenario simulation

\section{Introduction}

China is the world's largest fishery country, and marine fisheries are an important part of Chinese agricultural economy. However, because Chinese mariculture and marine ecological protection have not been carried out simultaneously, the negative interaction between fishery productivity and environmental carrying capacity has become prominent, and phenomena such as extensive aquaculture, sea eutrophication, overfishing and habitat destruction have become increasingly serious (Lin, 2012; Wang and $\mathrm{Hu}, 2013$; Liu, 2014). Marine ranches are meant to be harmonious with the environment and ecology, and integrate environmental protection, resource conservation, efficient production and recreational fisheries into a new marine economy (Yang et al., 2016), which provides practical possibilities for countries around the world to delay environmental degradation and increase economic output. This effective method has received wide attention from international scholars.

Throughout the development of marine ranching in various countries in the world, international scholars have conducted large-scale exploration and research on the development of marine ranching ecosystems, with fruitful results but large differences. Foreign scholars are mainly devoted to the study of in-depth fish life habits and the physical and ecological properties of fish reefs (Felley et al., 2008; Kim et al., 2013), while Chinese scholars are mainly devoted to the research of marine ranch site selection, artificial reef selection and biological control and domestication technology. Scholars have been exploring marine ranches more and more deeply. The research of marine ranch ecosystems has made great progress and major breakthroughs in many aspects. Through summary and discovery: 
In terms of release methods, the transition from single multiplication and release to highquality seed selection and timely stocking has been realized (Hong et al., 2009; Pan et al., 2010; Cheng and Jiang, 2010); in seed breeding, it has successfully moved from cage culture research to seawater stocking research (Wood and Peschken, 1990; Holby and Hall, 1994; Ottera et al., 1998; Rørvik et al., 2000; Luo and Fang, 2019); in research sites from indoor experimental exploration to practical simulation research on the sea area (Rubio et al., 2014; Taylor et al., 2016; Yu et al., 2016; Chen et al., 2018); in environmental restoration from passive damage restoration to active adjustment and maintenance. However, despite the abundant research results of marine ranch breeding, release and ecological engineering technology, there is still a lack of research on marine ranch ecosystem theory and management models. Currently, short-term single-disciplinary theoretical and technical experimental investigations are the main focus, and less analyze the operating mechanism of marine ranching ecosystems from the perspective of ecosystem integrity, especially the lack of long-term, continuous, and dynamic system studies, resulting in serious conflicts between economic output, ecosystems, and marine environments in the construction of existing marine ranches.

This paper takes Dalian Zhangzi Island Marine Ranching as an example. By constructing a marine ranching ecosystem dynamic model, this article explores the evolution mechanism and elastic process of the marine ranching ecosystem from the perspective of an artificial ecosystem. Based on the adaptive cycle principle, multi-scenario simulation simulates the optimal marine ranching the maximum economic output provides a feasible theoretical basis and operational specifications for the sustainable development of marine ranches.

\section{Materials and Methods}

\section{Study area}

Zhangzi Island in Changhai County is located at $124^{\circ} 47^{\prime}$ east longitude and $39^{\circ}$ north latitude. It covers an area of approximately $14.3595 \mathrm{~km}^{2}$. It is surrounded by islands such as Zhangzi Island, Dalian Island, Big Mouse Island, and Small Mouse Island. Zhangzi Island is close to the two major fishing grounds in Liaoning (Haiyang Island Fishing Ground and Bohai Bay Fishing Ground), about 56 nautical miles away from Dalian. Zhangzi Island is located in the mid-latitude zone between the Eurasian continent and the Pacific Ocean (Figure 1). It has a sub-humid monsoon climate in the northern temperate zone with significant monsoons and plenty of sunshine. The sea area of Zhangzi Island is affected by the ocean monsoon climate, the air is mild and humid, the temperature difference between day and night is small, and the frost-free period is relatively long up to about 220 days. The annual average temperature in the sea area of Zhangzi Island is about $10^{\circ} \mathrm{C}$, the coldest month is January, the average temperature is minus $7.1^{\circ} \mathrm{C}$; the hottest month is August, the average temperature is $25.3^{\circ} \mathrm{C}$. The average annual rainfall in the sea area of Zhangzi Island is $633 \mathrm{~mm}$, and the rainfall is concentrated in July, August and September each year (Zhang et al., 2020).

The economy of Zhangzi Island has gradually developed from a collective economy formed by marine fishery and its affiliated industries to a collective enterprise focusing on marine economic product breeding, marine transportation, and product processing. The sea area of Zhangzi Island is located at 39 degrees north latitude and belongs to the Yellow Sea waters. It is the largest sub-planting and multiplication area of Yesso scallop (Mizuhopecten yessoensis) in China. Over the years, adhering to the ecological concept of "cultivating the sea for thousands of hectares and raising the sea for thousands of years", it has now developed into a large-scale, standardized, world-class modern marine ranch covering an area of 1,600 
square kilometers. Its ecological value and practical results have won worldwide attention and recognition (Sun et al., 2018). Zhangzi Island Marine Ranch has a national Yesso scallop seed field and 5 improved breeding bases. It mainly produces scallops, abalones, sea cucumbers, Zhangzi Island oysters, real sea squirts and other sea treasures. There are more than 6 billion second-level seed of scallops, contributing more than $70 \%$ of the total profit. In 2015, the Yesso scallop fishery on Zhangzi Island passed the MSC sustainable fishery standard certification, becoming the first fishery in China to obtain the international sustainable fishery standard certification. The Yesso scallop germplasm was created and the improved species expanded, making it the first batch of pollution-free water in the country. The output of products ranks the leading level in the country. As the core product of Zoneco Group Company Limited (Co., Ltd.), Yesso scallop is an important profit growth point for the company. Table 1 shows the income of the Yesso scallop project of Zhangzi Island Marine Ranch. It can be seen from the table that Zoneco Group Co., Ltd. saw a significant increase in the annual income of the "Yesso scallop project" from 2006 to 2017, and the income was good. After 2011, the annual income of the Yesso scallop has declined significantly. In recent years, due to the "lost" event of the Yesso scallop, the income of the Yesso scallop project has dropped sharply. Zoneco Group Co., Ltd. issued a performance bulletin, and the announcement showed that the company lost 399 million yuan in 2019 and made a profit of 32.11 million yuan in the same period last year, a decrease of $1341.79 \%$. The "lost" incident of the Zhangzi Island Yesso scallop has brought huge losses to the local economic construction and residents' lives. It is urgent to restore the balanced development of the ecological and economic construction of the Zhangzi Island marine ranches.

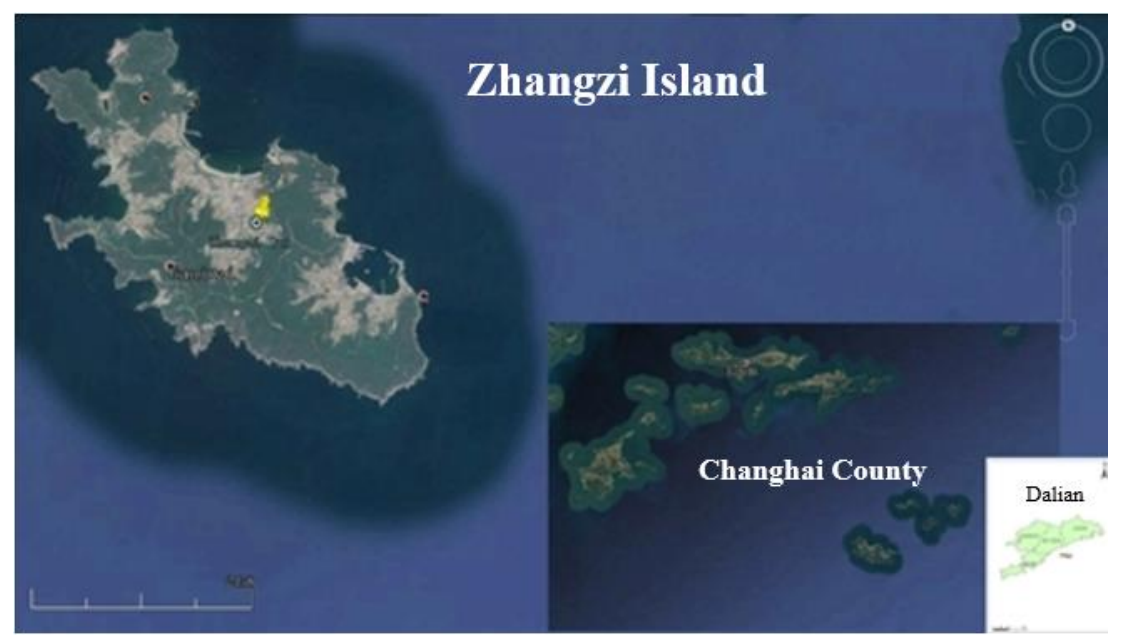

Figure 1. Geographical location map of Zhangzi Island research area

Table 1. Income of Yesso scallop project of Zoneco Group Company Limited

\begin{tabular}{c|c|c|c}
\hline Year & Income (EUR) & Year & Income (EUR) \\
\hline 2006 & 54444761.6634 & 2011 & 152088884.5049 \\
2007 & 47266839.3439 & 2012 & 135976920.8247 \\
2008 & 54702576.0626 & 2013 & 123328608.7526 \\
2009 & 71253161.9311 & 2017 & 98857521.5235 \\
2010 & 116469204.9177 & & \\
\hline
\end{tabular}




\section{Research methods and data sources}

\section{Research methods}

Marine ranching is a complex dynamic system coupled by the three of natural society and artificial society. Conventional experiments cannot accurately simulate and predict the endogenous changes and stress mechanisms of complex giant systems. System Dynamics originates from cybernetics, which was created by Wienes. In 1956, Professor J. W. Frerester of Massachusetts Institute of Technology (MIT) based on system theory, absorbed the essence of cybernetics and information theory, and formally established the discipline of system dynamics. System dynamics model (SD) is established by the Massachusetts institute of technology in system theory, information theory, cybernetics and computer technology as the foundation, according to the state of the system, control and information feedback to reflect the dynamic mechanism of the actual system, and through the establishment of simulation model, using a scientific method of computer simulation experiment was carried out. As a non-phenomenological "affair" method, SD can use the system structure, the causal relationship of each link and the feedback loop to establish a comprehensive conceptual model, and solve the system performance through simulation, combining qualitative and quantitative methods. System Dynamics has two distinct characteristics: endogenous and feedback, which is very effective for solving high-order, multi-loop and nonlinear complex feedback system problems (Xiong et al., 2013, 2016; Zhang et al., 2015). The dynamic changes of marine ranching ecosystems are highly consistent with the evolutionary laws of complex feedback systems, so it is a good choice to study the integrity of marine ranching ecosystems from the perspective of system theory. This paper uses the system dynamics method to simulate the marine ranching ecosystem to fill the gap in the marine ranching field to grasp the evolution process and mechanism of the system through simulation, and to provide ideas for longterm, dynamic and strategic simulation research.

\section{Data sources}

This article adopts an objective attitude and corresponding methods to conduct on-site visits, and uses relevant data collected from field investigations as the main data source for marine ranching ecosystem simulation research. The rest of the data comes from the "China Fishery Statistical Yearbook" (2010-2016), "Statistical Yearbook of Fishery Production in Dalian, Liaoning Province" (2010-2016); "Annual Report of Zoneco Group Co., Ltd."; partly derived from existing literature estimates and project survey data; partly derived from table function determination, and other parameters Based on the model multiple simulation runs.

\section{Construction of a marine ranching artificial ecosystem model}

As one of the main economic fish and shellfish exported by Dalian Zhangzi Island Marine Ranching, Yesso scallop are not only the key to ensuring a stable and balanced marine ecological environment, but also an important guarantee for promoting local social and economic development. However, in recent years, the annual yield of Yesso scallop from the Zhangzi Island Marine Ranching in Dalian has severely restricted the local economic development and affected the biological and ecological balance of the sea area of Zhangzi Island. Based on this, this article mainly builds a Yesso scallop growth and development model with predictive function around the Yesso scallop food chain. Searching for the elasticity of marine ranches through model operation and exploring the 
maximum output of Yesso scallop has certain guiding significance for realizing the friendly and sustainable development of the social economy and marine ecology of Dalian Zhangzi Island.

\section{System boundary and structure}

There is frequent material exchange, energy conversion and information transmission activities between the internal components of the marine ranch ecosystem, and between the interior and the surrounding environment. Therefore, the marine ranch ecosystem is not a closed and isolated space, but an open complex giant system. The goal of this research is to explore the optimal and maximum output of the Yesso scallop. Therefore, the boundary of the system is delineated according to the research needs, and the factors closely related to the Yesso scallop are included in the system as endogenous variables. The external environmental factors affecting the growth and development of the Yesso scallop were regarded as exogenous variables. Figure 2 is a block diagram of the marine ranch system model structure, which mainly reflects the predation relationship between the internal components of the Yesso scallop ecosystem, the regulation effect of benthic saprophytes on water quality, the stress of water temperature changes on aquatic organisms, the influence of human and natural factors on the nutrient content and the influence of artificial fishing on the yield of Yesso scallop. Due to the mobility of seawater in the ocean and the connectivity of the marine ranch system, the model boundaries are not strictly divided by region. Only endogenous and exogenous variables are included in the marine ranch ecosystem model, so that the system constitutes one closed circuit, for system dynamics simulation study.

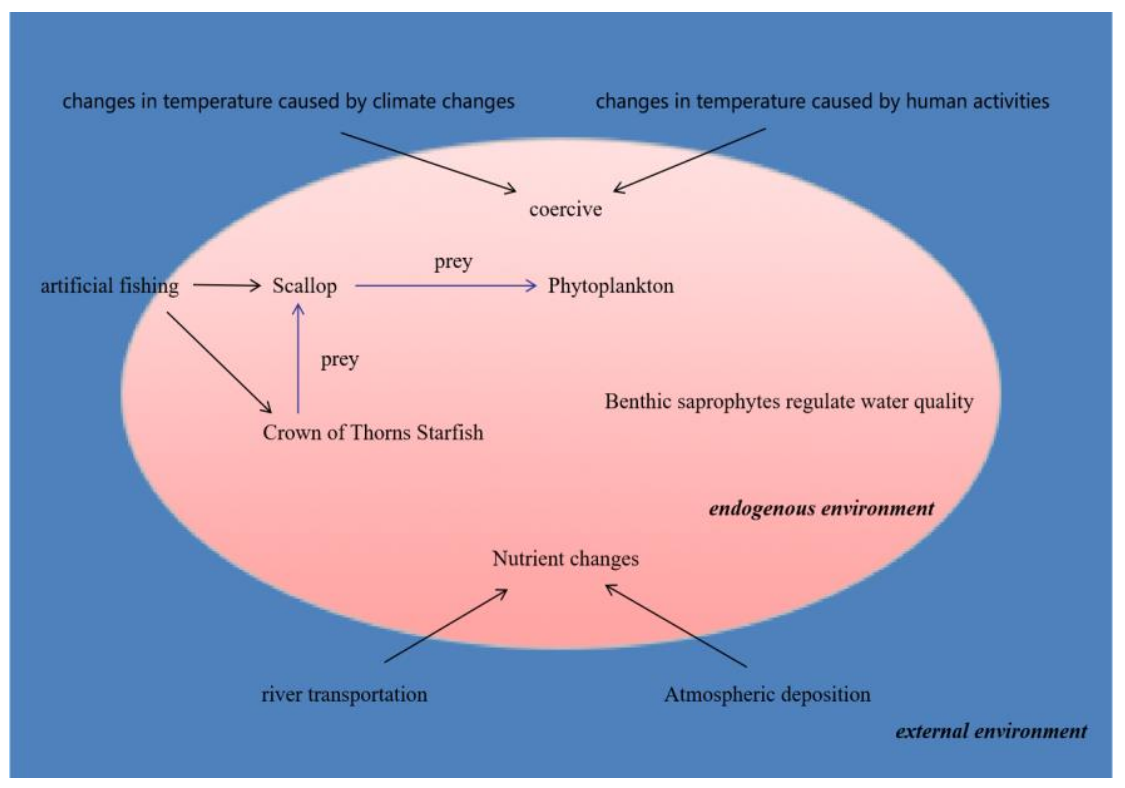

Figure 2. Block diagram of marine ranch system model

As phytoplankton is the main food source of Yesso scallop, it directly limits the population of Yesso scallop. Long thorn starfish (Acanthaster planci) is the main natural enemy of Yesso scallop. Real-time monitoring of Yesso scallop is a prerequisite for controlling the production of Yesso scallop. Therefore, the endogenous variables of the system model are composed of the Yesso scallop food web, which can be divided into 
plankton groups and benthic organisms. The number of plankton, the number of Yesso scallop, the number of long thorn starfish, and the number of benthic saprophytes are mainly (Table 2). As the most important factor in the marine ecosystem model, Yesso scallop not only provide support for social and economic development, but also a key influencing factor to ensure the stability of the marine ecological environment. Therefore, based on the integrity of the ecosystem, this paper divides the marine ecosystem into three parts: the Yesso scallop ecological subsystem, the socioeconomic subsystem, and the environmental subsystem. The simulation work of the marine ranching artificial ecosystem of the Yesso scallop is carried out.

Table 2. A brief table of internal and external growth variables of marine ranching Yesso scallop system model

\begin{tabular}{c|c}
\hline Endogenous variables & Exogenous variables (factors) \\
\hline $\begin{array}{c}\text { Number of plankton } \\
\text { Number of Long thorn Starfish }\end{array}$ & $\begin{array}{c}\text { Regional climate change influencing factors (storm surge, water } \\
\text { temperature, etc.) } \\
\text { Number of benthic saprophytes } \\
\text { Value of economic investment funds (economic investment, } \\
\text { output value, etc.) }\end{array}$ \\
$\begin{array}{c}\text { Factors affecting the development of the Yesso scallop } \\
\text { environment construction (base construction coefficient) }\end{array}$ \\
\hline
\end{tabular}

Sudden changes in regional climate, resulting in over-cold or over-heated seawater temperature, will affect the spawning rate of Yesso scallop and slow the development of Yesso scallop. Affected by global climate change, the occurrence of natural disasters such as typhoons will also have a certain impact on the stability of the marine ranching ecosystem. Therefore, the exogenous variables of the system model are determined by the environmental factors of Yesso scallop, human intervention, and economic development. The composition mainly includes regional climate change, human activities, economic investment, etc. (Table 2). Taking into account the complexity of the marine ranching ecosystem, through preliminary research and literature review, comprehensive consideration of the internal elements and external factors of the system, and appropriately simplified the Yesso scallop ecological subsystem and its interaction with the environment, social and economic subsystems relationship.

System dynamics believes that the behavior mode and characteristics of the system mainly depend on the internal dynamic structure and feedback mechanism. On the basis of the above-mentioned system model boundary and structure analysis, according to the specific physical and economic geography of the study area, a qualitative analysis of the internal structure of the marine ecosystem is carried out to further study the cause and effect between the various components of the marine ranching ecosystem model positive and negative feedback relationship. The causal circuit diagram of the marine ranching system model is shown in Figure 3.

(1) Implementation of marine ranching technology $\rightarrow+$ artificial reef construction $\rightarrow$ + phytoplankton $\rightarrow+$ scallops

(2) Implementation of marine ranching technology $\rightarrow+$ artificial reef construction $\rightarrow$ + benthic detrital organisms $\rightarrow+$ inorganic salt content $\rightarrow+$ phytoplankton $\rightarrow+$ scallops

(3) The implementation of marine ranching technology $\rightarrow$-long thorn starfish $\rightarrow+$ scallops 
(4) The implementation of marine ranching technology $\rightarrow+$ marine ranching investment $\rightarrow+$ scallops $\rightarrow+$ GDP $\rightarrow+$ marine ranching innovation research $\rightarrow+$ marine ranching technology implementation

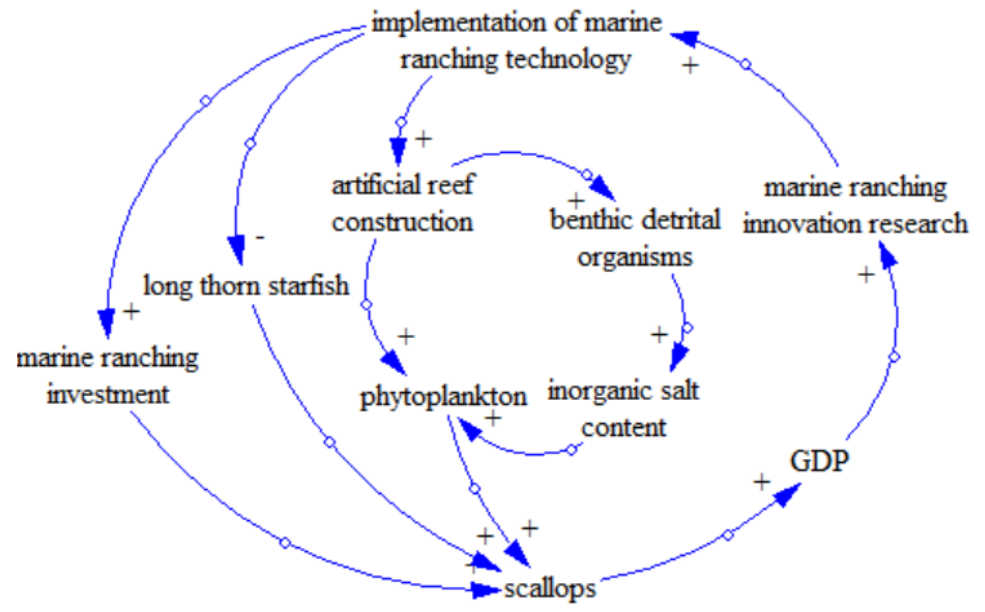

Figure 3. Causal circuit diagram of marine ranching system model

The causal chain 1 is a positive feedback causal chain that characterizes the ecological process of marine ranches, which means that artificial reefs in marine ranches can provide a living environment for phytoplankton and Yesso scallop, and promote their growth and development. The causal chain 2 is a positive feedback causal chain that characterizes the water quality environment of marine ranches, which means that benthic detrital organisms in the marine ranching artificial ecosystem can not only regulate the water quality environment, but also ensure sufficient food to ensure the normal growth and development of the Yesso scallop. The causal chain 3 is a negative feedback causal chain of the ecosystem. The increase in the number of long thorn starfish leads to a decrease in the number of Yesso scallop. Therefore, a monitoring system is set up to control the number of long thorn starfish in real time to ensure the survival rate of the Yesso scallop. The causal chain 4 is a positive feedback causal chain that represents the socio-economic characteristics of marine ranches. The initial investment in marine ranching technology can increase the production of Yesso scallop, thereby driving local GDP to attract the government to increase construction efforts and speed up innovative research on marine ranches. Form an ecological-economic virtuous circle.

\section{Structural analysis}

Dalian Zhangzi Island Marine Ranch relies on the natural ecological proliferation of the sea to cultivate Yesso scallop to increase the output of fishery resources, thereby driving local economic development. Comprehensively considering the internal elements of the system and the main external factors, the model is divided into marine ecological subsystems, social economic subsystems and environmental subsystems. The social economic subsystem and the environmental subsystem jointly restrict the ecological subsystem, and the ecological subsystem has different degrees of feedback to the social economic subsystem and the environmental subsystem. The marine ecology-socioeconomic-environmental coupling study is the basis for the overall study of the Zhangzi Island marine ranching and a prerequisite for a more comprehensive study of the marine ranching, which can make the model output more realistic and closer to reality. 


\section{Marine ecological subsystem}

Zhangzi Island marine ranching ecosystem mainly describes the growth process of plankton, Yesso scallop, long thorn starfish, and benthic detrital organisms: the model sets that the supplement of Yesso scallop larvae comes from mature Yesso scallop spawning and artificial breeding release. The number of Yesso scallop is limited by food sources, natural enemies long thorn starfish and living space. Lack of food, excessive number of long thorn starfish, and exceeding the ecological capacity of living space may cause the migration or death of Yesso scallop, causing serious economic losses. If the long thorn starfish multiplies too fast, it will pose a great threat to the survival and development of the Yesso scallop. Therefore, a long thorn starfish monitoring mechanism is set up in the marine ranching to monitor the number of long thorn starfish in real time to prevent more long thorn starfish from invading. The model sets that the long thorn starfish has two death methods: natural death and man-made fishing. Benthic detrital organisms can decompose marine animal and plant debris into inorganic matter, so that the residual energy can be reused by phytoplankton, etc. and can maintain the material circulation and energy flow of the ecosystem. The model sets that the number of benthic detrital organisms mainly depends on the birth rate, mortality, and control of predation factors by natural enemies.

\section{Socioeconomic subsystem}

The social and economic benefits of marine ranches are mainly based on the maximum output of the shellfish. By optimizing marine fishery resources, the social and economic growth will be promoted, and the recreational projects of marine ranches will also promote the development of social economy. The social and economic investment has increased the scale of marine ranches, and the monitoring system is more advanced and complete. Artificial seedlings and seedling selection are developed under the guidance of excellent scientific research to develop more cost-effective and labor-saving methods, so that the social economy and marine ranching operations can feed back and make progress together.

\section{Environmental subsystem}

Environmental stress factors mainly include non-optimum temperature, lack of the nutrients and natural disasters. Yesso scallop seedlings are extremely sensitive to temperature. Seawater temperature below $5^{\circ} \mathrm{C}$ or higher than $25^{\circ} \mathrm{C}$ will affect the Yesso scallop seedlings and even cause death. The nutrient content of seawater has a certain impact on the growth process of the oyster shellfish. The bloom phenomenon caused by the excessive nutrient salt concentration will pose a great threat to the life of marine organisms, which can cause suffocation or poisoning. Natural disasters such as storm surges, tsunamis, and sudden climate changes have a great impact on the growth and development of marine ranches including the Yesso scallop. The artificial habitat construction of the Yesso scallop and the prevention of natural disasters can directly affect the economic benefits of the Yesso scallop.

\section{Flow graph construction and model verification}

Vensim is owned by Ventana Systems, Inc. A graphical interface software for visualized, documented, simulated, analyzed, and optimized dynamic system model was 
developed. Based on the Vensim system dynamics software, the dynamic flow diagram of the marine ranch ecosystem is drawn, as shown in Figure 4.

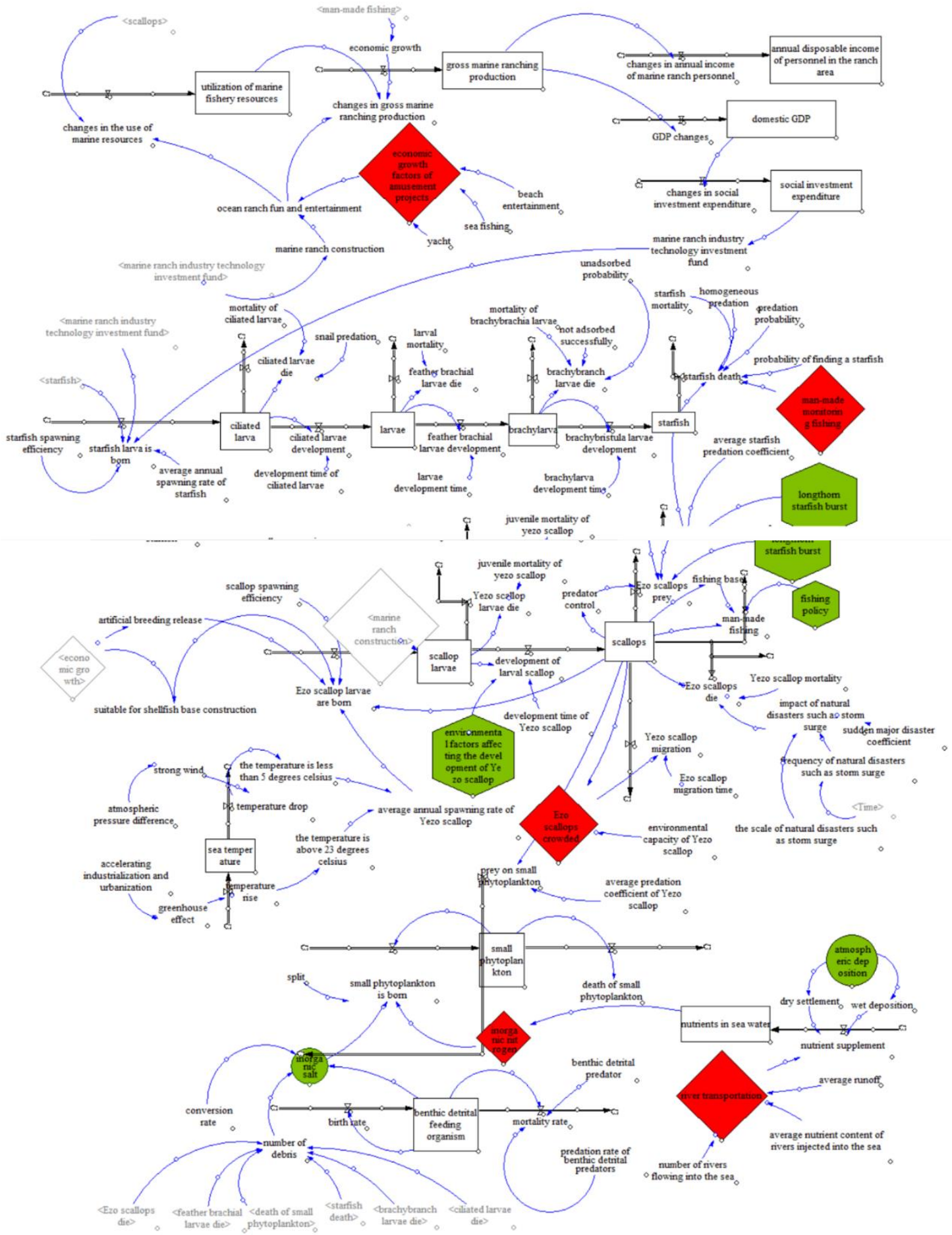

Figure 4. Systematic flow diagram of Zhangzi Island marine ranching system

After the model is established, it is particularly important to verify the authenticity of the model according to the purpose-related validity test (Wang and Zhang, 2020). After the repeated debugging process of "simulation operation-verification-correction- 
simulation operation" and the process of consulting experts, this research passed the following inspection contents:

1. Structural test. Through the rationality inspection of the system model boundary, variable parameters and logical relationship, it is found that the system model boundary and variable simplification degree is relatively appropriate, and the feedback relationship is basically consistent with the natural development law of things; 2 . Behavioral test. Through testing of different modes such as direct operation of the model, testing of extreme conditions, sensitivity analysis, etc., the marine ranching ecosystem model basically restores the behavior patterns observed in the actual marine ranching, and found that human interference under environmental changes and other scenarios, the system expectation is similar to the actual situation; 3. Authenticity check. Since the model construction involves part of the historical data of the study area, part of the historical data of the study area is used to verify the authenticity. After the operation simulation of the model, combined with the annual report data of the Zhangzi Island marine ranching and relevant literature analysis, the simulated data and the real data are combined the dynamic development trend is analyzed to verify that the fit between the two is relatively good (Table 3, Figure 5).

Table 3. Comparison data of simulated annual output and actual annual output of Yesso scallop

\begin{tabular}{c|c|c|c|c|c}
\hline Year & Simulation value & Actual value & Year & Simulation value & Actual value \\
\hline 2006 & 233.21 & 244.8 & 2010 & 1713 & 2580 \\
2007 & 377.01 & 750.2 & 2011 & 3452 & 3500 \\
2008 & 630.5 & 1203 & 2012 & 6099 & 5894 \\
2009 & 1040 & 1729 & 2013 & 8172 & 7486 \\
\hline
\end{tabular}

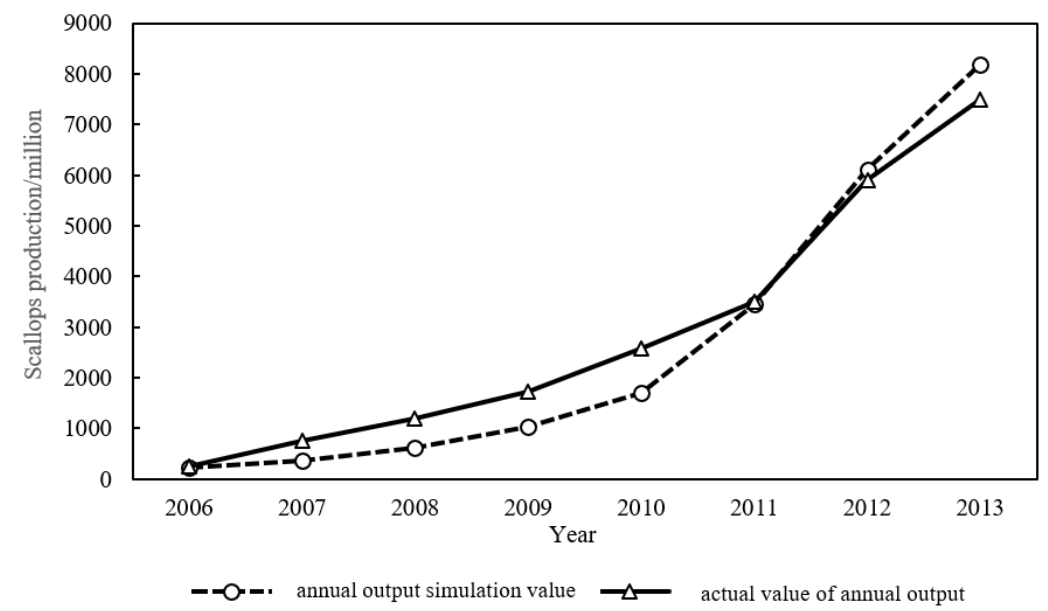

Figure 5. Comparison diagram of annual output fitting of Yesso scallop

\section{Results}

\section{Basic simulation and the results of marine ranching ecosystem model}

The object of the analogue simulation research is Zhangzi Island marine ranching. The period simulated in the model is from 1996 to 2040, with a time step of 0.5 year. According to the reversed data resources mentioned before, several main initial value settings of the 
model is that there are initially 4,000,000 Yesso scallop larvae, and 500 crown-of-thorns starfish. The initial amount of phytoplankton is $2,000 / \mathrm{L}$.

Based on the causality and parameter values of the model and for the time being ignored the other external factors, the SD model of the marine ranching is simulated dynamically (Figure 6). The basic simulation results show that the changing increasing speed of the Yesso scallop's quantity is from stable to exponential and stable again. Before 2004, while the initial constructed marine ranching, the output amount of Yesso scallop is stably 4,000,000 per year, which cannot meet the markets' needing. The state of imbalance between supply and demand restricts development. As the developing of marine ranching and the increase of artificial intervention, setting good artificial reefs to providing better growing environment, the Yesso scallop's increasing rate becoming exponential before reaching environment capacity, the output can be 8.9 billion, 2225 times to the initial amount. After 2014, the amount of Yesso scallop reached environment capacity, the quantity become stable, the output remains at around 10 billion. With the continuous improvement of scientific and technological means and innovative research in marine ranches, marine ranches are equipped with corresponding monitoring systems to monitor the invasion of long thorn starfish. If the main enemy of Yesso scallop, long thorn starfish migrate into the marine ranch breeding area, the marine ranch The management staff will take measures such as timely fishing to achieve the purpose of timely stop loss and ensure that the Yesso scallop are in an ideal living condition. After increasing the environmental capacity of the Yesso scallop in the marine ranch ecosystem through manual intervention, the number of Yesso scallop will again show a substantial increase. This shows that putting artificial reefs to build marine ranches can effectively increase the yield of Yesso scallop and bring significant economic benefits.

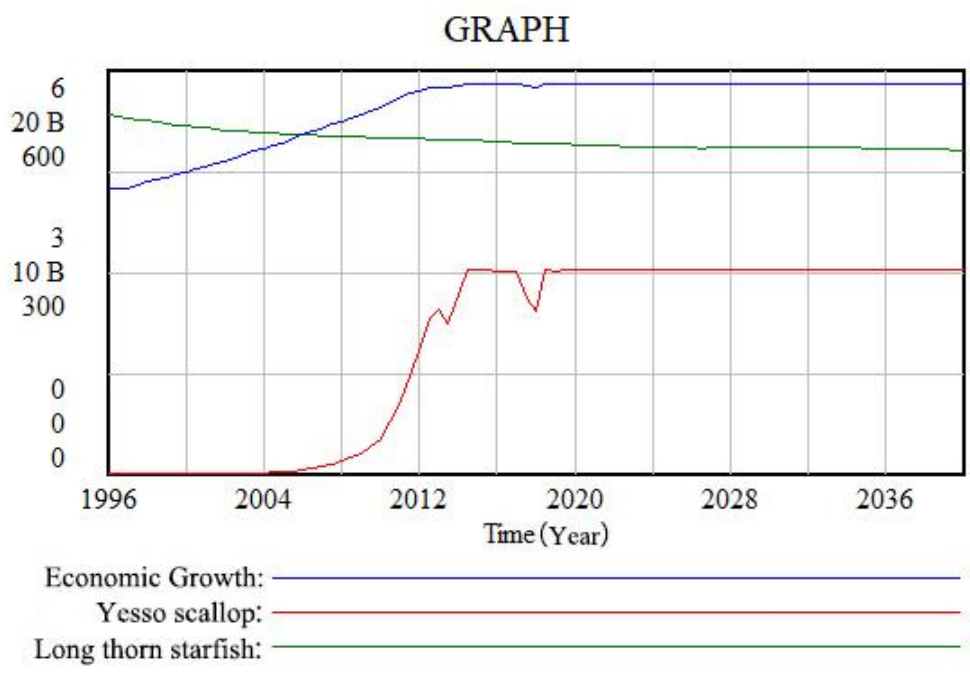

Figure 6. Simulation output of Zhangzi Island marine ranching economic growth Yesso scallop starfish

\section{The sensitivity analysis of marine ranching ecosystem model}

The sensitivity analysis can directly simulate the observed variables' sensitivity to the controlled variables and the function trace by marine ranching ecosystem model. The most important factor can be known through model's sensitivity tests and influence analysis to ground the amorous scenario diagnosis restore and adaptive management. There are 5 main control variables (uncertain variables) in this research to perform 
sensitivity test and the influence degree of Yesso scallop: fishing policy, environmental factors of Yesso scallop's growth, sudden weighty natural disaster probability, and outbreak probability of crown-of-thorns starfish, atmospheric deposition. All those became the theoretical base of continuing amorous scenario simulation; specific regulatory parameters are Table 4 and Table 5.

Table 4. Sensitivity test setup profile

\begin{tabular}{|c|c|c|c|c|c|}
\hline Control variables & $\begin{array}{c}\text { Initial } \\
\text { value }\end{array}$ & $\begin{array}{c}\text { Regulation } \\
\text { sector }\end{array}$ & Times & Distribution & $\begin{array}{l}\text { Observed } \\
\text { variables }\end{array}$ \\
\hline Fishing policy & 0.5 & $0.25-0.7$ & 200 & $\begin{array}{c}\text { Mean random } \\
\text { distribution }\end{array}$ & Yesso scallop \\
\hline $\begin{array}{l}\text { Environmental factors of } \\
\text { Yesso scallop' s growth }\end{array}$ & 1 & $0.5-1$ & 200 & $\begin{array}{l}\text { Mean random } \\
\text { distribution }\end{array}$ & Yesso scallop \\
\hline $\begin{array}{l}\text { Sudden weighty natural } \\
\text { disaster probability }\end{array}$ & 0 & $0-1$ & 200 & $\begin{array}{l}\text { Mean random } \\
\text { distribution }\end{array}$ & Yesso scallop \\
\hline $\begin{array}{l}\text { Outbreak probability of } \\
\text { crown-of-thorns starfish }\end{array}$ & 0 & $0-1$ & 200 & $\begin{array}{l}\text { Mean random } \\
\text { distribution }\end{array}$ & Yesso scallop \\
\hline Atmospheric deposition & 0.2 & $0.1-0.4$ & 200 & $\begin{array}{l}\text { Mean random } \\
\text { distribution }\end{array}$ & Yesso scallop \\
\hline
\end{tabular}

Table 5. Formulations involved in control variables in sensitivity test

\begin{tabular}{|c|c|}
\hline Control variables & Formulation \\
\hline Fishing policy & Artificial fishery $=$ fishing policy $*$ fishing fundament $*$ Yesso scallop \\
\hline $\begin{array}{l}\text { Environmental factors of Yesso } \\
\text { scallop's growth }\end{array}$ & $\begin{array}{c}\text { Yesso scallop larva growth= Yesso scallop larva /time of grow } * \text { relevant } \\
\text { environment factors }\end{array}$ \\
\hline $\begin{array}{l}\text { sudden weighty natural disaster } \\
\text { probability }\end{array}$ & $\begin{array}{l}\text { natural disaster coercion }=\text { natural disaster probability *Storm surges } \\
\text { and other disasters' scale* Storm surge and other disasters' frequency }\end{array}$ \\
\hline $\begin{array}{l}\text { outbreak probability of crown- } \\
\text { of-thorns starfish }\end{array}$ & $\begin{array}{l}\text { Starfish predation amount on Yesso scallop }=\text { Starfish } * \text { Starfish mean } \\
\text { predatory coefficient }+ \text { Starfish } * \text { crown-of-thorns starfish outbreak } \\
* 500 * \text { Starfish mean predatory coefficient }) * \text { predatory control }\end{array}$ \\
\hline atmospheric deposition & $\begin{array}{l}\text { dry deposition }=\text { atmospheric deposition } * 0.23 \\
\text { wet deposition }=\text { atmospheric deposition } * 0.2\end{array}$ \\
\hline
\end{tabular}

The sensitivity analysis of the model can choose the scenario factor resources, prepare for the marine ranching system scenario simulation, ensure scenario factors and the combination, and ensure the range of the parameters. As Figure 7 shows, a,b,c,d are atmospheric deposition, fishing policy, environmental impact, coefficient of sudden major natural disasters, Yesso scallop sensitivity test results. The sensitivity analysis of the marine ranching system model shows that atmospheric factors nearly not influent the Yesso scallop's growth, fishing policy, environmental factors of Yesso scallop's growth, sudden weighty natural disaster probability, outbreak probability of crown-of-thorns starfish are sensitive factors. The annual amount of Yesso scallop and the trend of amount are big by those factors.

\section{The amorous scenario simulation of marine ranching ecosystem model}

Different scenarios can be settled to simulate different evolutionary mechanism by changing relevant parameters in the amorous scenario simulation to get the main factors of Yesso scallop's amount. According to sensitivity analysis, fishing policy, there are 4 main control variables which affect the amount: environmental impact, sudden weighty natural disaster probability and outbreak probability of crown-of-thorns starfish. Different scenario 
disturbance model can be artificial adjusted to base for diagnose and reserve policy. There are artificial disturbance and ecosystem's positive and negative feedback adjustments affect the marine ranching Yesso scallop culture. Based on sensitivity analysis, through artificial and environmental disturbance, control 4 control variables to precede amorous scenario simulation experiment. The threshold of the Yesso scallop's death can be found and used for amorous scenario simulation of marine ranching ecosystem through many model running and adjust variables.

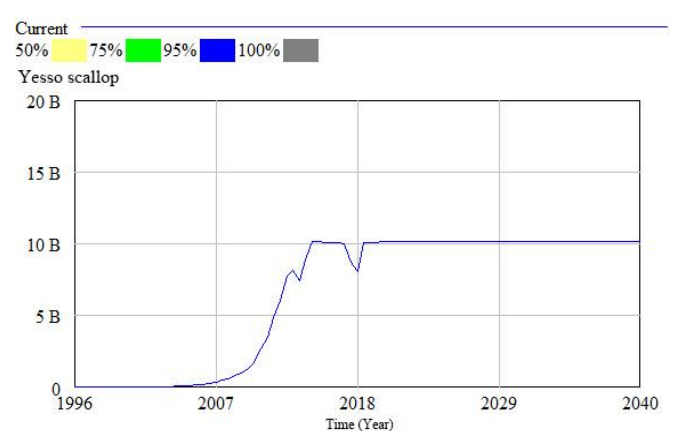

$\mathbf{a}$

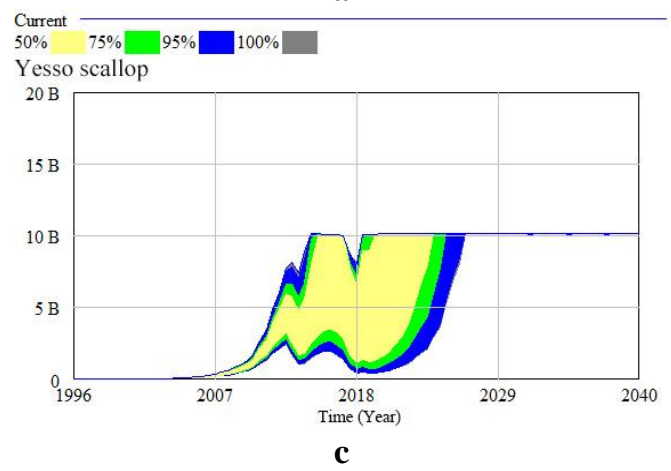

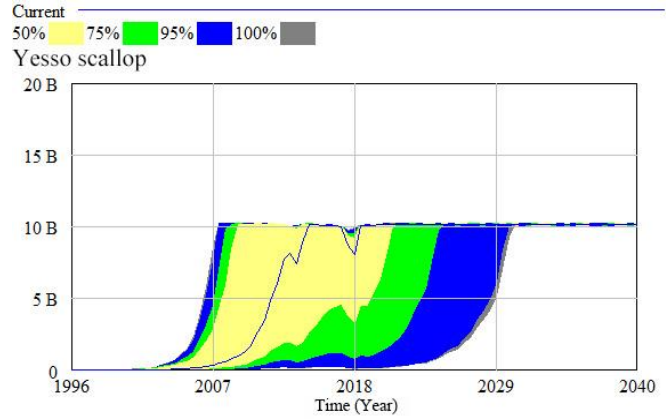

b

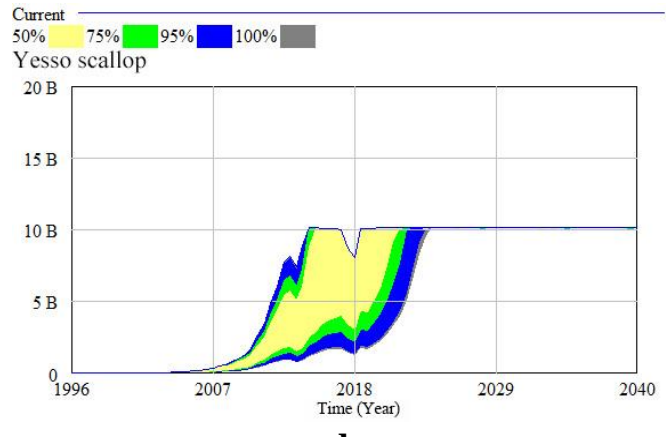

d

Figure 7. Atmospheric deposition, fishing policy, environmental impact, sudden weighty natural disaster probability and Yesso scallop sensitivity test results

\section{Scenario simulation of artificial activity}

Marine ranching as an artificial ecosystem, artificial activities effect the fishes' growth and breed. Further experiments carried on 2 variables which are fishing policy and environmental factors of Yesso scallop in order to fully understand how the artificial disturbance effect marine ranching ecosystem. Set the threshold of fishing policy is 0.9, the threshold of environmental factors of Yesso scallop's growth is 0.07. Adding experts' views and local experiments within each threshold of fishing policy and environmental factors of Yesso scallop choose a changing interval to get the maximum and minimum value to visual simulation. Specific control variable parameters are in Table 6.

Table 6. Human activity disturbance scenario control variable parameter table

\begin{tabular}{c|c|c|c|c}
\hline \multirow{2}{*}{ Number } & Control variables & \multirow{2}{*}{ Present value } & \multicolumn{2}{|c}{ Control value } \\
\cline { 4 - 5 } & & & $\mathrm{A}$ & $\mathrm{B}$ \\
\hline 1 & Fishing policy & 0.5 & 0.8 & 1.2 \\
2 & Environmental factors of Yesso & 1 & 0.1 & 0.5 \\
\hline
\end{tabular}


(1) disturbance by a single factor

From fishing policy scenario A1 and B1 in the Figure 8, the change of fishing policy greatly affects the output of Yesso scallop. Long thorn starfishes are still monitored by the marine ranching monitoring system, and they are caught when they are found. The number of starfish in the marine ranching waters is decreasing year by year. The local economic growth rate become slowly because of the slow rate of Yesso scallop's grow amount which is effected by slightly adjust fishing policy (A1). The slow economic growth trend has led to a decrease in the investment in the construction and research of marine ranching. The research and practice of the seedling, release, and subsistence environment of the Yesso scallop has been slow. It will not be until 2026 that the production of Yesso scallop has increased in a wide range. The economy grew steadily. When sharp rise the fishing policy (B1), long thorn starfishes are still monitored by the marine ranching monitoring system, and they are caught when they are found. The number of starfish in the marine ranching waters is decreasing year by year. The economic growth and Yesso scallop's amount both decrease fast, the amount in 2006 is merely 2719. To guarantee the sustainable production of Yesso scallop, stop over fishing it can stop the decrease of production. After resuming normal production and development, the amount can be 340,000 in 2040 , which is a quarter of the initial amount. The local economy is also showing a downward trend due to the reduction in the production of Yesso scallop. However, because the local economic benefits are also related to the recreational projects of the marine ranching, the basic business status of the marine ranch is guaranteed to a certain extent, and the local economic loss is reduced. The additional economic benefits of marine ranches can continue to be used in the construction of the Yesso scallop culture area, providing a suitable growth and development environment for the Yesso scallop, so that it can still grow slowly under the large-scale fishing policy. Slightly increase fishing amount can extend the time of fast growing Yesso scallop amount, greatly increase fishing amount can decrease the Yesso scallop's total amount.
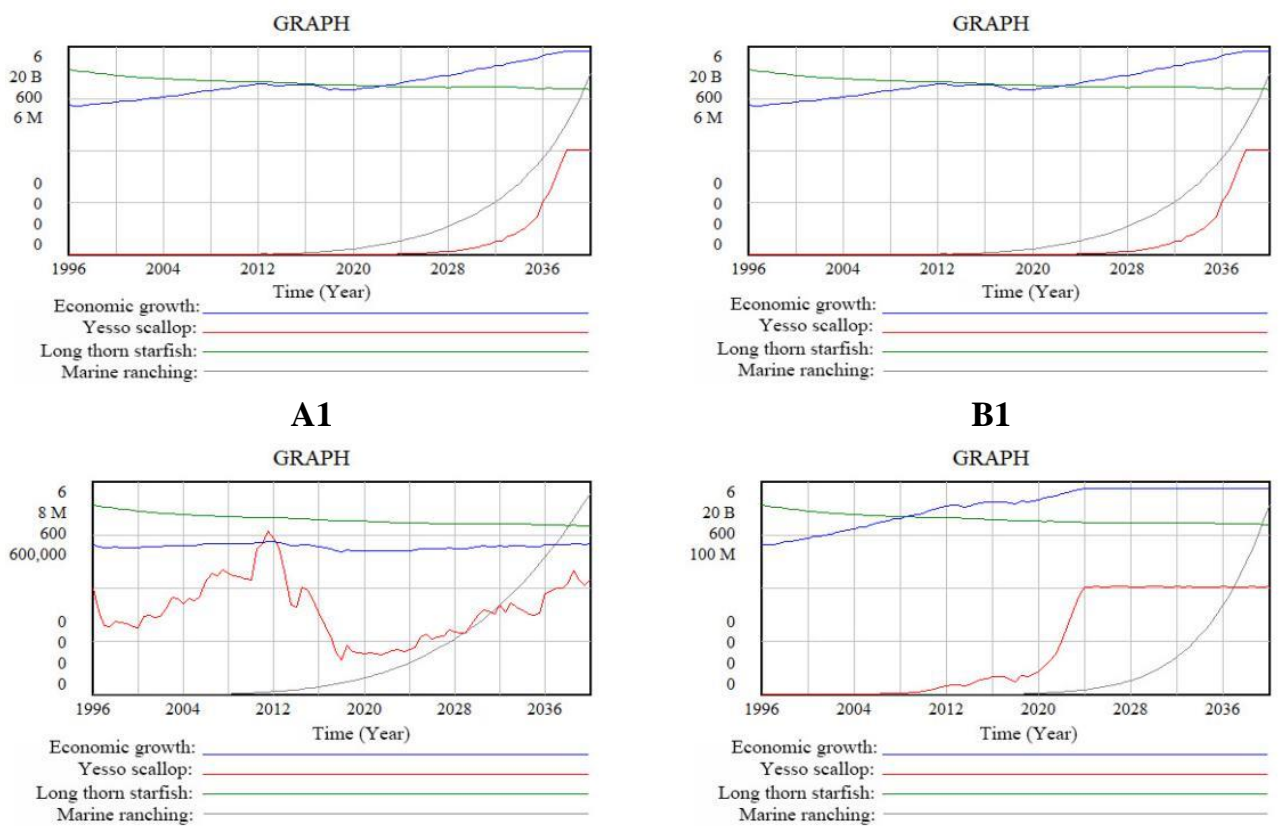

A2

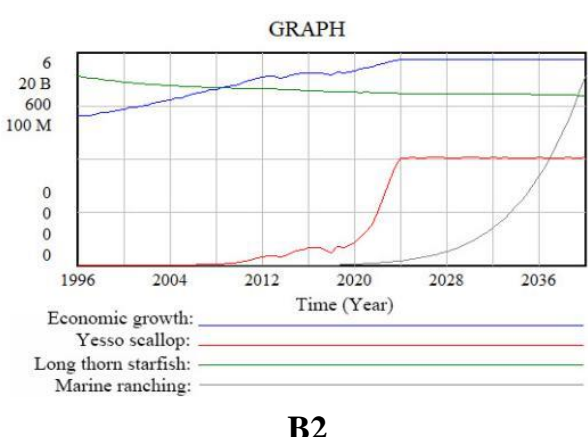

Figure 8. Simulation results of single factor disturbance in the scenario of human activity interference 
From the scenario of environmental factors of Yesso scallop's growth A2 and B2 in the Figure 8, the change of environment can directly affect the growing process and total amount. Greatly changing the environmental factors of Yesso scallop's growth (A2), can make the amount change from increase to decrease, the economic curve also decreases. After the Yesso scallop reached the environmental capacity in 2011, due to insufficient food and space resources, the Yesso scallop began to migrate or even die. By 2018, the output of the Yesso scallop was only 1 million. Long thorn starfishes are still monitored by the marine ranching monitoring system, and they are caught when they are found. The number of starfish in the marine ranching waters is decreasing year by year. With the accumulation of capital, the construction curve of marine ranches has grown rapidly. Marine ranches have gradually implemented measures to improve the bottom quality of the sea Yesso scallop culture, expand the breeding space, and ensure adequate food. The current situation of substantial reduction in production due to insufficient resources and growth space, the production of Yesso scallop has gradually recovered from 2019 and entered a state of steady growth. It is expected that the production will reach 6 million in 2050. Slightly regulating the development of environmental factors in the early stage will limit the growth and development of the Yesso scallop (B2), which greatly restricts the growth of the Yesso scallop, and the yield growth trend is slow. Long thorn starfishes are still monitored by the marine ranching monitoring system, and they are caught when they are found. The number of starfish in the marine ranching waters is decreasing year by year. The production of Yesso scallop in 2003 was 35 million pieces, and the yield curve gradually showed an increasing trend since then. Around 2020, the construction of marine ranching has been vigorously developed. After breaking the original environmental factors, the production of Yesso scallop has increased sharply. After about four years, it will reach a new dynamic balance, at which time the output will reach about 10 billion. It can be seen that the slight adjustment of the developmental environmental factors has delayed the development of marine ranches to a certain extent, and has a lagging effect on the production of Yesso scallop and local economic growth. Substantial adjustments to the developmental environmental impact factors will break the original ecological balance, cause severe fluctuations in the production of the Yesso scallop, and severely restrict local economic growth.

(2) disturbance by double factor

Combining fishing policy and environmental factors of Yesso scallop's growth to make a two-factor disturbance scenario simulation fatherly analyze the Yesso scallop's influence by changing of fishing policy and environmental factors of Yesso scallop's growth. The scenarios are in Table 7.

Table 7. Parameter table of two-factor control variables for artificial disturbance scenarios

\begin{tabular}{l|l|l}
\hline A1A2 & 0.8 & 0.1 \\
A1B2 & 0.8 & 0.5 \\
B1A2 & 1.2 & 0.1 \\
B1B2 & 1.2 & 0.5 \\
\hline
\end{tabular}

The scenario A1A2 in the Figure 9 shows that while slightly change the fishing policy and greatly change the environmental factors, the Yesso scallop grows slowly, and cannot meet the lost after fishing. Long thorn starfishes are still monitored by the marine ranching 
monitoring system, and they are caught when they are found. The number of starfish in the marine ranching waters is decreasing year by year. The amount of Yesso scallop constantly decreases, the population is merely 55096 in 2018, the economic growth decrease, too. Artificial intervals improve the marine environment to make sure the Yesso scallop can grow and breed normally, and avoid the extinction of Yesso scallop, which fully shows the advantage of marine ranching. The scenario A1B2 in the Figure 9 shows that, while slightly change the fishing policy and the environmental factors, there is little effect on Yesso scallop's growing and the economic grow with it. In the former stage the Yesso scallop is affected by fishing policy, but thanks to the good environment, the output steadily grows and can be $21,940,000$ in 2014. After the population reach the environmental capacity and continue the fishing, the output obviously decreases, but the good marine ranching environment makes sure the exponential output growth of Yesso scallop, thus the local economic can grow whit it. The scenario B1A2 in the Figure 9 shows that, while greatly change the fishing policy and the environmental factors, the effect of Yesso scallop and local economic is severe. Long thorn starfishes are still monitored by the marine ranching monitoring system, and they are caught when they are found. The number of starfish in the marine ranching waters is decreasing year by year. The output and population of Yesso scallop decrease largely, the local economic decrease severely, too. When the large scale of fishing and sever environment happen, the output decrease and population is merely 50 in 2023. Though there is huge development of marine ranching, the environment and fishery still restrict the growth of Yesso scallop. The scenario B1B2 in the Figure 9 shows that, while greatly change the fishing policy and slightly change the environmental factors, the output and local economic also decrease. Comparing to B1A2, though the output decrease, the speed is low because of the good environment. The development of marine ranching improves the environment, and after 2016, the output grows slowly.

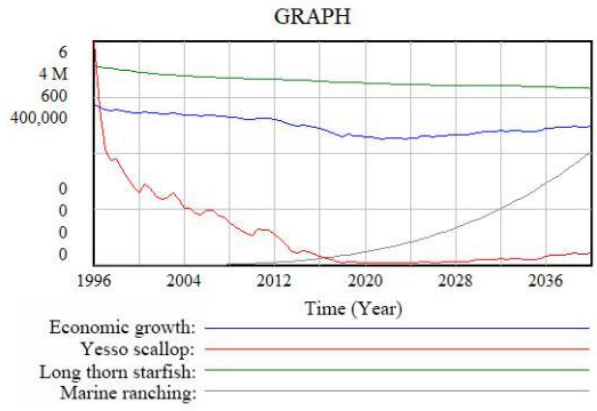

A1A2

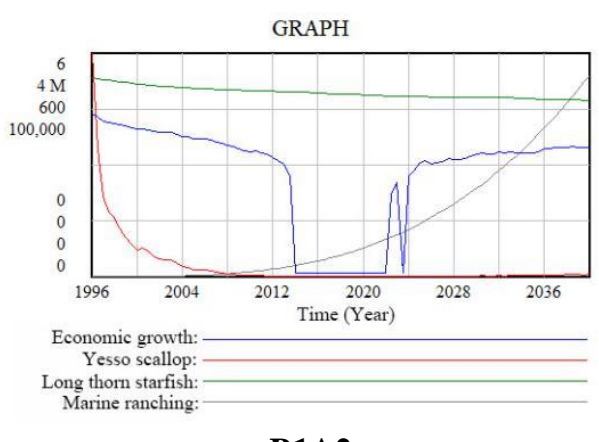

B1A2

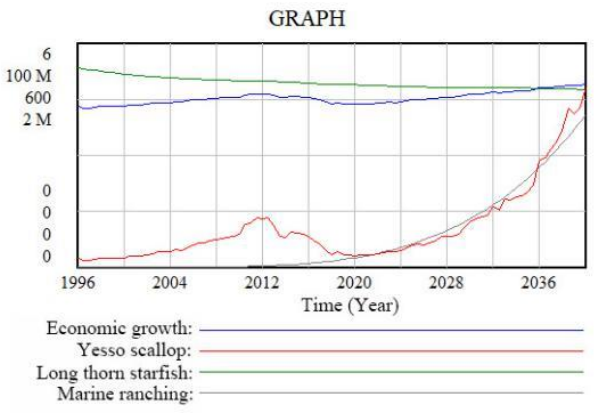

A1B2

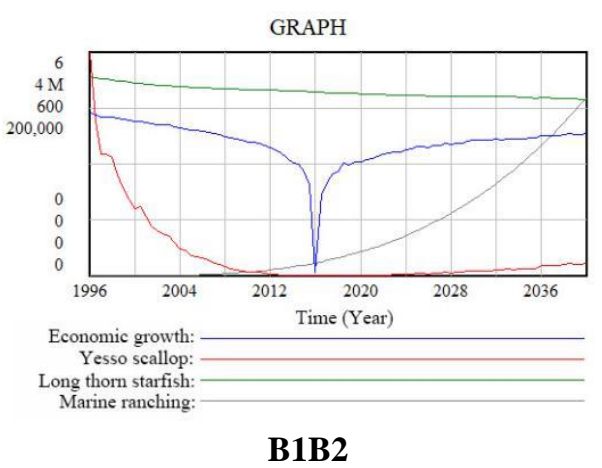

Figure 9. Simulation results of two-factor disturbance under the condition of human activity disturbance 


\section{Ecological environment disturbance scenario simulation}

The cultivation of Yesso scallop under the disturbance of ecological environment is an important research direction for the management of marine ranches and ensuring the yield of Yesso scallop. The sudden outbreak of natural enemies of Yesso scallop and the arrival of large-scale natural disasters seriously endanger the life and safety of Yesso scallop. Therefore, the single factor disturbance of sudden major natural disaster coefficient and crown-of-thorns starfish burst coefficient is simulated, and the threshold method is still used to select the regulation interval, and the threshold value of sudden major natural disaster coefficient is 3.2. The threshold value of crown-of-thorns starfish burst coefficient is 1.95 . The regulation range of sudden major natural disaster coefficient is 1-4, and that of crown-of-thorns starfish burst coefficient is 0.1-0.26. See Table 8 for details.

Table 8. Parameter table of regulating variables of ecological environment disturbance scenario simulation

\begin{tabular}{c|c|c|c|c}
\hline \multirow{2}{*}{ Serial Number } & Regulatory Variable & $\begin{array}{c}\text { Present } \\
\text { Value }\end{array}$ & \multicolumn{2}{|c}{ Regulatory Value } \\
\cline { 3 - 4 } & Coefficient of sudden major natural \\
disasters & 0 & 1 & B \\
\hline 2 & $\begin{array}{c}\text { Burst coefficient of crown-of-thorns } \\
\text { starfish }\end{array}$ & 0 & 1.5 & 1.95 \\
\hline
\end{tabular}

From the scenarios A3 and B3 of sudden major natural disasters (Fig. 10), it can be seen that different coefficients of sudden major natural disasters will reduce the total yield of Yesso scallop to varying degrees. A slight adjustment of the sudden major natural disaster coefficient A3 can make the production of Yesso scallop fall slightly and fluctuate obviously, reaching the lowest yield of 438270000 Yesso scallop in 2019. Long thorn starfishes are still monitored by the marine ranching monitoring system, and they are caught when they are found. The number of starfish in the marine ranching waters is decreasing year by year. With the addition of marine ranch construction, the resistance of Yesso scallop to sudden major natural disasters increased, and the variable index increased to a stable state to ensure the stable development of economy. When the sudden major natural disaster coefficient (B3) is greatly adjusted, there is a great threat to the growth and development of Yesso scallop. Sudden major natural disasters can destroy the living space of Yesso scallop, resulting in a sharp decrease in the yield of Yesso scallop, with a minimum value of 275277. Although the construction and restoration of marine ranches can improve the living environment of Yesso scallop, the yield increase rate of Yesso scallop is slow due to the large damage intensity of sudden major natural disasters. It can be seen that the slight regulation of sudden major natural disasters has little impact on Yesso scallop,and it can enter the state of value-added and maintain steady development as soon as possible after marine ranches are repaired and the environment is improved. However, greatly regulating the coefficient of sudden major natural disasters will greatly destroy the living space of Yesso scallop, even if it is added to the restoration of marine ranch, it will seriously lag behind the local economic development.

It can be seen from the scenarios A4 and B4 of the crown-of-thorns starfish outbreak in 2012 that the crown-of-thorns starfish will significantly reduce the production and local economy of Yesso scallop, but the yield can still be restored and maintained stable in the 
later stage. Small-scale explosions of crown-of-thorns starfish will cause fluctuations and decline in the production of Yesso scallop, which will lead to small fluctuations in the local economy (A4). Small-scale outbreaks of crown-of-thorns starfish can be eliminated as soon as possible, after the complete elimination of crown-of-thorns starfish, Yesso scallop resume to grow to the environment and remain stable. The large-scale outbreak of crown-of-thorns starfish will lead to a sharp increase in the number of crown-of-thorns starfish when food is abundant and no natural predators are caught (B4). Due to the large number of crown-of-thorns starfish and a wide range of predation, the yield of Yesso scallop has dropped sharply to 125509, and the local economy has dropped below the initial value, which is only half of that in the bumper harvest year. Due to the excessive number of crown-of-thorns starfish, the yield of Yesso scallop continued to grow slowly even during the construction of marine ranches, and the yield did not increase significantly until the initial results of the new construction of marine ranches in 2026, and reached a new environmental capacity in 2033. It can be seen that the crown-of-thorns starfish, as the survival natural enemy of the Yesso scallop, has little impact on the yield and the local economy when the quantity can be controlled, but the growth and development of the Yesso scallop is greatly affected after the large-scale outbreak, which restricts the local economic development to a great extent.

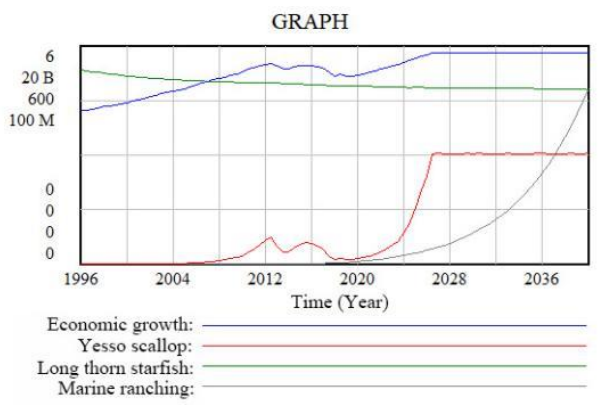

A3

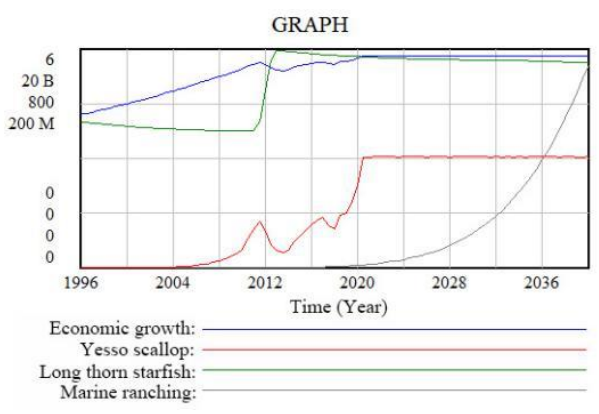

A4

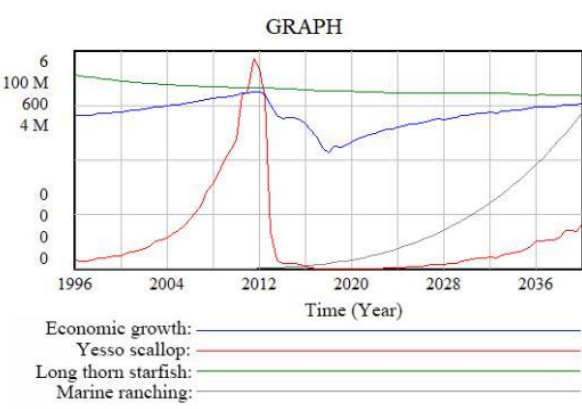

B3

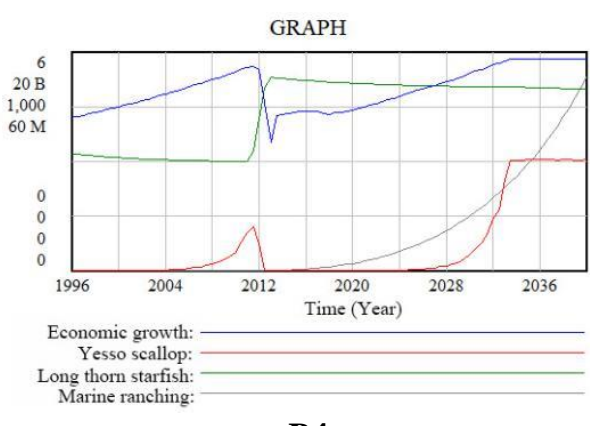

B4

Figure 10. Simulation results of single factor disturbance in ecological environment disturbance scenario

\section{Conclusion}

This paper takes the overall marine ranches artificial ecosystem of Zhangzi Island as the background, from the point of view of ecosystem integrity, combined with the multiple feedback effects of food chain, human intervention and environmental change at the core of Yesso scallop. The system dynamics model is used to simulate the marine ranch artificial ecosystem of Zhangzi Island and the following conclusion are drawn: 
The simulation and diagnosis of the feedback mechanism of Zhangzi Island marine ranches artificial ecosystem by system dynamics provides a feasible method for analyzing the overall evolution process of marine ranch ecosystem.

The basic scenario simulation shows that the implementation of marine ranch construction has a significant effect on the proliferation of Yesso scallop, and the total yield of Yesso scallop can be increased to 2500 times of the initial value.

Fishing policy, environmental factors affecting the development of Yesso scallop, sudden major natural disaster coefficient and crown-of-thorns starfish are the sensitive factors that have great influence on the yield of Yesso scallop in the model, which lays a theoretical foundation for follow-up multi-scenario simulation.

The simulation results of human disturbance scenarios show that overfishing can lead to the depletion of Yesso scallop, and a good living environment is conducive to the restoration of normal growth of Yesso scallop.

The simulation results of ecological environment disturbance show that sudden major natural disasters and large-scale outbreaks of crown-of-thorns starfish can cause destructive destruction to Yesso scallop, but the number of crown-of-thorns starfish and the degree of protection from disasters can be controlled artificially by constructing marine ranches, which can help the Yesso scallop recover its yield slowly.

Through the basic simulation and multi-scenario simulation of the model, the temporary environmental capacity of Yesso scallop shrimp was judged and the main factors affecting the yield of Yesso scallop shrimp were simulated. This research believes that: A. Marine ranching is a dynamic artificial ecosystem, and follow-up research should pay more attention to the complexity and integrity of the system to deeply study the internal operating mechanism and dynamic changes of the system. B. A good growth environment, including adequate food source, is conducive to promoting shrimp reduced Yesso scallop to ocean waters to ranch accommodation environment, but also break the existing ecological system of dynamic balance, the higher the powerful guarantee of ecosystem balance, so should pay attention to repair and improve the growth environment of the shrimp, reduced Yesso scallop, to ensure the shrimp Yesso scallop production steadily improving. C. In order to ensure that Yesso scallop shrimp can survive largescale in severe natural disasters, it is suggested to strengthen the follow-up construction of marine ranch to consolidate the base of Yesso scallop shrimp and further research on disaster prevention, so as to make the yield of Yesso scallop shrimp increased significantly. D. In order to avoid the severe loss of production caused by the outbreak of natural enemies, it is suggested to continue to strengthen the research on the monitoring system of Marine ranches, timely protect the Yesso scallop from invasion by foreign enemies, and maintain the yield safety of the Yesso scallop. E. A good Marine ranching management system is the cornerstone for the construction of Marine ranching. The management department should formulate reasonable fishing policies, strengthen fishery resource management system, ensure the healthy growth of Yesso scallop and promote the sustainable development of fishery resources.

\section{Discussion}

In this paper, the food chain of Yesso scallop in the marine ecosystem is taken as the core structure flow chart. Due to the problem of too wide coverage, other economic fish and shellfish in the marine ranch are not included. At the same time, the crown-of-thorns starfish is the top predator in the sea area, and the natural enemy of the crown-of-thorns 
starfish, the giant triton, is not added. In order to improve the model, other fishery organisms will be added to the follow-up study and the domestication system will be added for simulation. In addition, there are few environmental factors in this paper, and most of them are replaced by one factor of natural disaster. Therefore, it is impossible to judge the impact of various other environment factors on Yesso scallop and the response mechanism of Yesso scallop. In the follow-up study, we can refer to the Chinese and foreign literature more, through the study of the impact of marine natural disaster on other organisms transition to marine ranches and through countless running simulations to get the optimal parameters to improve and optimize the model.

Acknowledgements. This article is supported by the study on Engineering Technology of Planning, Construction and Management for Marine Ranching in Guangdong Province(GML2019ZD0402). We gratefully thank for helping and supporting.

\section{REFERENCES}

[1] Chen, Z. M., Mao, P. S., Yan, J., Wu, Y. Y., Wu, S. J. (2018): The technology process and design method of modern marine cage and ranching. - Guangdong Shipbuilding 37(2): 4649, 77.

[2] Cheng, J. H., Jiang, Y. Z. (2010): A Review and prospect of Marine living resources proliferation and release. - Chinese Fisheries Science 17(3): 610-617.

[3] Felley, J. D., Vecchione, M., Wilson, R. R. (2008): Small-scale distribution of deep-sea demersal nekton and other megafauna in the Charlie-Gibbs Fracture Zone of the MidAtlantic Ridge. - Deep Sea Research Part II Topical Studies in Oceanography 55(1-2): 153-160.

[4] Holby, O., Hall, P. O. J. (1994): Chemical fluxes and mass balances in a marine fish cage farm. III. Silicon. - Aquaculture 120(3-4): 305-318.

[5] Hong, B., Sun, Z. Z., Zhang, Y. P., Zeng, Z. C., Tian, Z. Q. (2009): Evaluation on the effect of multiplication and release of fishery resources in the upper reaches of Huangpu river. Aquatic science and technology information 36(4): 178-181.

[6] Kim, S. K., Yoon, S. C., Youn, S. H., Park, S. U., Corpus, L. S., Jang, I. K. (2013): Morphometric changes in the cultured starry flounder, Platichthys stellatus, in open marine ranching areas. - Journal of Environmental Biology 34(2): 197.

[7] Lin, G. J. (2012): "Big country effects" of Chinese fisheries concerning with their characteristics, strategy and policy making. - Fishery Information \& Strategy 27(4): 264271.

[8] Liu, H. (2014): Research on marine fisheries' contribution to marine economy in China. Ocean University of China.

[9] Luo, Y., Fang, Q. W. (2019): Transformation of traditional aquatic enterprises to marine ranches. - Ocean and Fishery 2: 45-46.

[10] Ottera, H., Kristiansen, T. S., Svasand, T. (1998): Evaluation of anchor tags used in searanching experiments with atlantic cod (Gadus morhua L.). - Fisheries Research (Netherlands) 35(3): 237-246.

[11] Pan, X. W., Yang, L. L., Ji, W. W., Liu, Z. L. (2010): Research progress of multiplication and release technology. - Jiangsu Agricultural Sciences 4: 246-250.

[12] Rørvik, K-A., Steien, S. H., Saltkjelsvik, B., Thomassen, M. S. (2000): Urea and trimethylamine oxide in diets for seawater farmed rainbow trout: effect on fat belching, skin vesicle, winter ulcer and quality grading. - Aquaculture Nutrition 6(4): 247-254. 
[13] Rubio, F., Kamp, L., Carpino, J., Faltin, E., Loftin, K., Molgó, J., Aráoz, R. (2014): Colorimetric microtiter plate receptor-binding assay for the detection of freshwater and marine neurotoxins targeting the nicotinic acetylcholine receptor. - Toxicon 91: 45-56.

[14] Sun, Q. C., Tan, Y. H., Li, J. B. (2018): Ecological protection and exploration of island in China in new era. - Ocean Development and Management 35(8): 22-27.

[15] Taylor, A. L., Nowland, S. J., Hearnden, M. N., Hair, C. A., Fleming, A. E. (2016): Sea ranching release techniques for cultured sea cucumber Holothuria scabra (Echinodermata: Holothuroidea) juveniles within the high-energy marine environments of northern Australia. - Aquaculture 465: 109-116.

[16] Wang, X. J., Hu, Q. G. (2013): Analysis on the coordination degree between mariculture and marine ecological environment in China. - China's Rural Economy 11: 86-96.

[17] Wang, G., Zhang, H. H. (2020): Research hotspots and trends of marine ecosystem services based on bibliometrics. - Acta Ecologica Sinica 40(7): 2496-2505.

[18] Wood, L., Peschken, A. A. (1990): Aquaculture: Marine Farming of Atlantic Salmon. Geography 75(3): 211-221.

[19] Xiong, J. X., Chen, D. L., Peng, B. F., You, X. J. (2016): Temporal and spatial difference of dynamic simulation of ecological carrying capacity in Dongting lake region. - Economic Geography 36(4): 164-172.

[20] Xiong, Y., Li, J. Z., Jiang, D. L. (2018): Optimized decision-making of water resources supply and demand system in Changsha-Zhuzhou-Xiangtan urban agglomeration based on the analog simulation. - Acta Geographica Sinica 68(9): 1225-1239.

[21] Yang, H. S., Huo, D., Xu, Q. (2016): My view on the construction of modern Marine ranching. - Ocean and lakes 47(6): 1069-1074.

[22] Yu, J., Chen, P. M., Feng, X. (2016): Food habits and trophic levels for 4 species of economical shrimps in the pearl river estuary shallow waters. - Journal of Southern Agriculture 47(5): 736-741.

[23] Zhang, M. J., Guan, D. J., Su, W. C. (2015): Scenarios simulation and indices threshold determination of ecological security in three gorges reservoir based on system dynamics. Acta Ecologica Sinica 35(14): 4880-4890.

[24] Zhang, J. F., Cai, H. J., Zhao, Y. N., Chen, W. H., Hu, S. Q., Liu, Y., Liu, C. F. (2020): Seasonal variation in the total organic carbon contents and the $\delta 13 \mathrm{C}$ values of macroalgae in the rocky intertidal zone of the Zhangzi island. - Marine Sciences 44(2): 56-65.

\section{APPENDIX}

Average predation coefficient of scallop $=0.061325$

Small phytoplankton predation $=$ scallop shrimp $*$ scallop average predation coefficient

Small phytoplankton $=$ small phytoplankton are born - small phytoplankton die - small phytoplankton are eaten

Split $=1.02$

Small phytoplankton birth $=$ Small phytoplankton $*$ inorganic nitrogen $*$ inorganic salt $* 2.08222 *$ fission

Inorganic nitrogen $=$ nutrient salt in seawater $* 0.2+0.1$

Integ $=$ initial value of seawater nutrient supplement $=0.13$

Dry settlement $=$ atmospheric settlement $* 0.23$

Atmospheric deposition $=0.1$

Wet settlement $=$ atmospheric settlement $* 0.2$

Inorganic salt $=0.01 * \mathrm{LN}(1+\mathrm{ABS}$ (benthic Detritus feeding organisms $*$ quantity of detritus $*$ conversion rate))

Conversion rate $=0.24$

Detritus quantity $=$ (death of small phytoplankton + death of starfish + death of short carpal larvae

+ death of feathered carpal larvae + death of shrimp scallop) $* 12$ 
Birth rate $=0.42 * \mathrm{LN}($ benthic detritus eater $)+14$

Integ $=$ birth rate - initial death rate of benthic detrital feeding organism $=7$

Benthic detritus feeding on natural enemies $=0.8$

Mortality rate $=$ (benthic detritus feeding organism + benthic detritus feeding organism natural enemies)* rate of benthic detritus feeding organism natural enemies

Predator predation rate of benthic detritus $=0.2$

Number of rivers flowing into seawater $=0.078$

River transport $=$ average nutrient content of rivers into the sea $*$ number of rivers into the sea $*$ average runoff

Nutrient supplement $=($ dry settlement + wet settlement $) *$ river transport

Average runoff $=0.75$

Average nutrient content in rivers into the sea $=0.2$

Atmospheric pressure difference $=0.3$

High wind $=$ atmospheric pressure difference $* 0.1+0.23$

Temperature less than $5{ }^{\circ} \mathrm{C}=$ temperature drop *0.13

Average annual spawning rate of scallop shrimp $=$ IF THEN ELSE(temperature above $23^{\circ} \mathrm{c}>=$ temperature below $5^{\circ} \mathrm{c}, 1,0$ )

Temperature above 23 degrees Celsius $=$ IF THEN ELSE(increase in temperature $>=23,1,0$ )

Temperature rise $=$ greenhouse effect $* 0.15$

Integ $=$ temperature rise - temperature fall Initial value $=-0.4$

Temperature reduction $=0.2 *$ DELAY1 (high wind generated, 2 )

Greenhouse effect $=$ accelerated industrialization and urbanization $* 0.1$

Industrialization, urbanization process plus $=1$

Economic growth $=0.2 * \mathrm{LN}(1+\mathrm{ABS}($ fished $* 423))+0.1$

Artificial breeding flow $=0.5^{*} \mathrm{LN}$ (economic growth)

Construction of suitable shellfish basement $=$ economic growth $* 0.64$

Scallop oviposition efficiency $=0.4$

Larvae birth $=$ artificial breeding release + scallop $*$ (spawning efficiency + average annual spawning rate of scallop) * suitable for shellfish basement construction

Marine ranching construction = Investment in Marine ranching industry and technology $* 0.00052$ Integ = larvae birth - larvae development - larvae death + initial value of marine ranch construction $=12$

Larva death $=$ larva mortality $*$ larva death

Larvae mortality rate $=0.23$

Development environment impact factor $=0.5$

Time of scallop development =RANDOM UNIFORM $(0.13,0.32,0.14)$

Larva development $=$ larva/developmental time $*$ environmental impact factors of scallop

Scallop crowding $=\operatorname{MAX}(0$, Scallop - scallop environmental capacity $)$

Predation control $=$ IF THEN ELSE $(>=50,1,0)$

Integ = young development of Scallop - artificial fishing - death of scallop - predation of scallop - initial migration value of scallop $=4 \mathrm{e}+006$

Scallop predation $=($ starfish $*$ average predation coefficient + starfish $*$ Long spiny Starfish outbreak $* 500 *$ average predation coefficient $) *$ Predation control

Fishing base $=$ IF THEN ELSE(scallop $>=60,1,0$ )

Manmade fishing $=$ fishing policy $*$ fishing base $*$ Prawn scallop

Fishing policy $=1.2$

Spiny starfish outbreak $=0$

Death of Scallop $=$ death rate of scallop $*$ death rate of scallop $*$ impact of natural disasters such as storm surge

Scallop mortality rate $=0.01$

Impact of natural disasters such as storm surge $=$ scale of natural disasters such as storm surge $*$ frequency of natural disasters such as storm surge + coefficient of sudden major disasters * scale of natural disasters such as storm surge * frequency of natural disasters such as storm surge 
Scallop migration $=$ Scallop crowding $/$ migration time

Scallop migration time $=0.02$

Environmental capacity of shrimp scallop $=1 \mathrm{e}+010$

Coefficient of sudden major disaster $=0$

Natural calamities such as storm surge frequency $=$ with look up $=$ timelookup $([(1996,0)-$ (2056,0.2)], (2010,0.06),0.11 (2011), (2012,0.09),0.88 (2013), (2014,0.09),0.06 (2015), (2017,0.98),0.094 (2020), (2030,0.094),0.094 (2040), (2050,0.094))

Scale of natural disasters such as storm surge $=$ RANDOM UNIFORM $(0.5,1.5,2)$

Starfish spawning efficiency $=0.24$

Starfish larvae birth $=$ starfish $*$ starfish spawning efficiency $*$ Starfish spawning efficiency $+10+\mathrm{LN}(\mathrm{ABS}$ (Investment in Marine Ranching Industry technology *0.0053))

Average annual spawning rate of starfish $=0.5$

Integ = Starfish larva birth - ciliary larva development - initial value of ciliary larva death 34

Ciliary larva death $=$ snail predation + ciliary larva $*$ ciliary larva death

Mortality rate of cilia larvae $=0.23$

Snail predation $=0.5$

Development time of ciliated larvae $=5$

Development of cilia larvae $=$ development time of cilia larvae/cilia larvae

Integ $=$ development of ciliary larva - development of carpal larva - initial value of death of carpal larva 32

Larvae mortality rate $=0.13$

Carpal larvae death $=$ carpal larvae $*$ Carpal larvae death

Development of carpal larvae $=$ development time of carpal larvae/carpal larvae

Development time of carpal larvae $=5$

Larvae with short wrists had a mortality rate of 0.3

Integ $=$ development of brachial larva - development of brachial larva - initial value of death of brachial larva 12

The unadsorbed probability is -0.24

Failed to adsorb 0.3

Death of brachiophora larva $=$ brachiophora larva $*$ unsuccessful adsorption + probability of failure + mortality of brachiophora larva)

Development of short carpal larvae $=$ short carpal larvae/short carpal larvae development time

Development time of short carpal larvae $=4$

Starfish mortality rate: 0.01

Starfish death $=($ starfish $*$ starfish death rate + catch by human monitoring $*$ probability of starfish discovery + probability of cannibalism by one species * probability of cannibalism by another species)

Starfish INTEg = Development of short carpal larvae - initial value of starfish death 534

Homogeneous predation

Species predation probability 0.01

Probability of finding starfish $=$ RANDOM UNIFORM $(0.01,0.8,0.01)$

Artificial surveillance fishing $=$ RANDOM UNIFORM $(0.4,5,4)$

Average predation coefficient of starfish $=20$

Investment in Marine ranching industry technology $=$ social investment expenditure $* 0.12$

Integ = larva development of Scallop - artificial fishing - death of scallop - predation of scallop initial migration value of scallop $4 \mathrm{e}+006$

Change in Marine resource utilization $=($ scallop with shrimp $) * 1000$

Integ = initial value of change of Marine fishery resources utilization 0.5

Manmade fishing $=$ fishing policy $*$ fishing base $*$ Prawn scallop

Economic growth $=0.2 * \mathrm{LN}(1+\mathrm{ABS}($ fished $* 423))+0.1$

Gross domestic product of Marine ranching = INTEg Initial value of gross domestic product change of Marine ranching 4234

Beach entertainment $=$ RANDOM UNIFORM $(0.1,1,0.3)$ 
Sea fishing $=$ RANDOM UNIFORM $(0.1,1,0.2)$

Yacht $=$ RANDOM UNIFORM $(0.1,1,0.3)$

Economic growth factor $=$ beach recreation + sea fishing + yacht

Marine ranching construction = Investment in Marine ranching industry and technology $* 0.00052$

Marine Ranching recreation $=$ Marine ranching construction + economic growth factor of recreational activities

Annual income changes of Marine ranchers = gross product of Marine ranches * 3.4E-005

Integ = Initial value of annual income variation of Marine ranchers

GDP change $=$ Marine ranching GDP $* 0.000108+354$

Domestic GDPinteg $=$ initial value of GDP change $=745654$

Change in social investment expenditure $=$ DOMESTIC GDP* 0.3

Integ = Initial change value of social investment expenditure $=32134$ 